\title{
The New Water Supply System of Rarotonga Cook Islands
}

\author{
Fan Yuzhu \\ Shanghai Municipal Engineering Design Institute (Group) Co,. Ltd \\ fanyuzhu@smedi.com
}

\begin{abstract}
The GoCI is committed to supplying reliable potable water to all properties connected to the water network by 2015. The benefits of a reticulated and treated water supply with storage are that the public health is improved, especially for the young, elderly and those with a medical condition, there is water available for usage during dry periods and that water is available for fire-fighting. The reliable supply of potable water engenders great opportunity to secure this resource to cater for population and economic growth and the continuing health of local communities. This paper shows a multi water source water supply system without energy and feed water only by gravity. The water treatment process described in this paper is simple and effective for the islands in the South Pacific Ocean.
\end{abstract}

Keywords-multi water source; gravity water supply system; water treatment; South Pacific Ocean; water management

\section{INTRODUCTION}

The Government of the Cook Islands is committed to supplying reliable potable water to all properties connected to the water network by 2015. The reliable supply of potable water affords an important opportunity to provide for population and economic growth and the continuing health of local communities.

The Government of the Cook Islands have recognised that the current system will need a new water supply system to realise this opportunity and have secured funds through a grant from the New Zealand Government and a loan from the People's Republic of China.

This commitment is substantial. It is the largest single infrastructure project in the Cook Islands since the international airport construction in 1974. As a legacy project it is important that the potable water system is designed to fulfil its obligations now, and for future generations.

This paper is introduction of the implement the Government of the Cook Islands policy of delivering potable water, reliably, to all properties connected to the existing water supply network.

This paper and design research is intended to:

- identify the deficiencies in the water supply network caused by deterioration of the existing network, changes in population growth and legislation; and

- $\quad$ analyse the deficiencies under current peak conditions and future peak water demand conditions, to determine appropriate solutions and associated costs.
This will enable a financial plan to be developed that identifies the costs of the required network upgrades and options for cost recovery.

This paper will provide immediate tangible benefits for the local community:

- An asset which is optimal in design so that it provides a reliable water source to all connected properties and continues to be economic to maintain and operate over the design life;

- Reliable treatment facilities that keep the local communities safe from pathogens, protozoa and viruses such as crypto, giardia and campylobacter within their drinking water; and

- Governance of the water network structured so that the Cook Islands are in a position to best manage this asset economically, politically, socially and environmentally.

- This project also harbours considerable opportunity to leave a legacy of education within the Cook Islands:

- Up-skilling of local people to operate and maintain the asset, so that more local jobs are created and reliance on outside resource is minimal; and

- Education of the local community on the importance of potable water, its preciousness as a resource and how, at a community level, they can seek to sustain it.

\section{EXISTING WATER SUPPLY SYSTEM}

\section{A. Descriptions}

Rarotonga's water network is supplied by spring and surface water intakes situated between 90 and $49 \mathrm{~m}$ above mean sea level (AMSL). The network can be described in terms of a hierarchy of pipes distributing water from the source to the end user. The system employs trunkmains to convey flow from the intakes down to the transmission network, consisting of interior and coastal ring mains and regular cross connections. Water users are supplied by a distribution network of smaller diameter sub-mains. There are 12 intakes in Rarotonga, the only measures for water treatment in the existing network are the coarse gravel screens at 8 of the intakes.

The existing ring main was constructed in 1967 / 1968 along the outer and inner coast road. The majority of the main 
is AC, with a small portion being uPVC. The sections in Avarua were replaced in 2012/ 2013 with DI and uPVC.

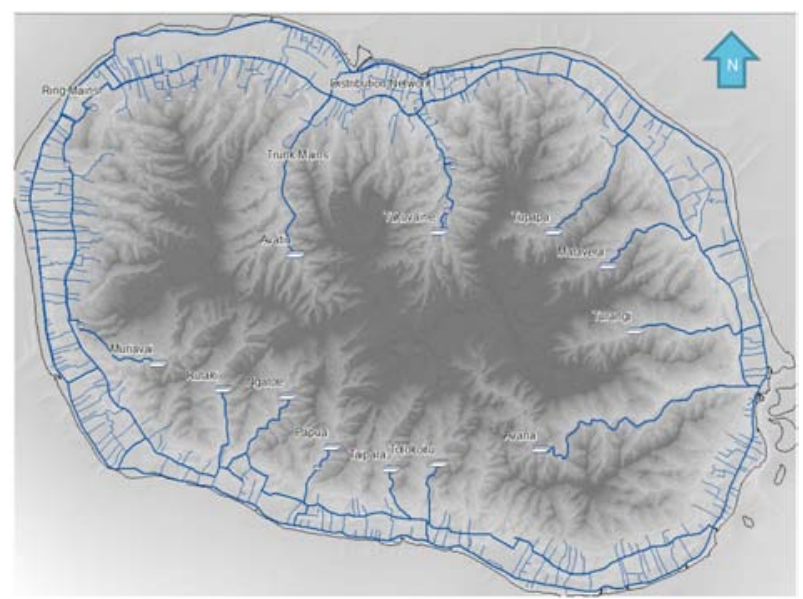

FIGURE 1 NETWORK OVERVIEW

\section{B. Hydraulic analysis of current system}

A hydraulic analysis was undertaken of the existing system. Total demand for 2013 excluding unaccounted for water is calculated to be $10,600 \mathrm{~m}^{3} / \mathrm{d}$. With an additional NRW demand of $4,100 \mathrm{~m}^{3} / \mathrm{d}$ the overall total demand is $14,300 \mathrm{~m}^{3} / \mathrm{d}$.

Rarotonga's existing network does not supply adequate pressure at peak demand and does not meet the proposed minimum levels of service.

Pressure problems are distributed right across the island and high velocities are predicted in both trunkmains and ringmains - refer to Figure 2.

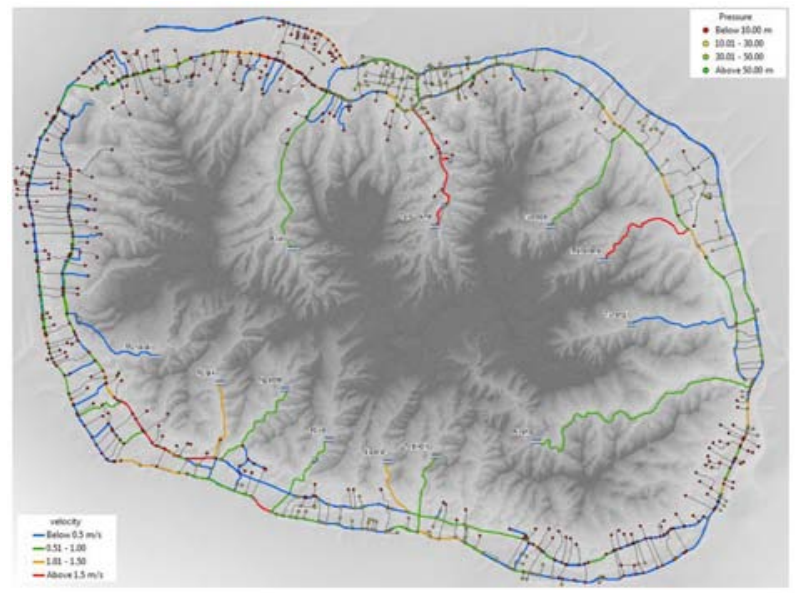

FIGURE 22013 NETWORK PERFORMANCE

A number of sections of ringmains and trunkmains exhibit velocities in excess of $1.5 \mathrm{~m} / \mathrm{s}$ with a maximum modelled velocity of $3.78 \mathrm{~m} / \mathrm{s}$. The most notable of these are the trunkmains from Takuvaine and Matavera and the ringmains in the southwest of the island and around Avarua in the northwest (these pipes are shown in red in Figure 2).

Ringmain pressures from Avarua to the southwest of the island and in the southeast all show pressures below the $10 \mathrm{~m}$ target pressure (these nodes are shown as red dots on the ringmains in Figure 2). This equates to $57 \%$ of the modelled nodes across the island.

\section{THE NEW WATER SUPPLy System}

\section{A. 2031 demand allocation}

The 2031 system incorporates the proposed CCECC ringmain upgrades as for the 2015 scenario. The future scenario also considers the hydraulic implications of proposed future projects. The three projects of greatest significance are the construction of storage reservoirs at each of Rarotonga's intakes, the construction of water treatment plants and the renewal of the trunkmains. The 2031 analysis assumes that the proposed upgrades will facilitate the effective function of the network as a fully pressurised system, preventing partially full pipe flow in the trunkmains and reducing water loss and the ingress of air and contaminants into the network.

Population projections for Rarotonga (Figure 3) suggest that the residential population of Rarotonga in 2031 may be approaching 13,000 if a high growth model is assumed. The demand assumptions developed in the Rarotonga Water Supply Technical Workshop (Te Mato Vai Technical, 2012) derive an estimate for domestic demand based on the residential population of 14,000 for 2031 allowing a contingency for growth. We has adopted these assumptions for the purposes of estimating future demand in the 2031 water supply network model (see Appendix A for a summary of the technical workshop outcomes).

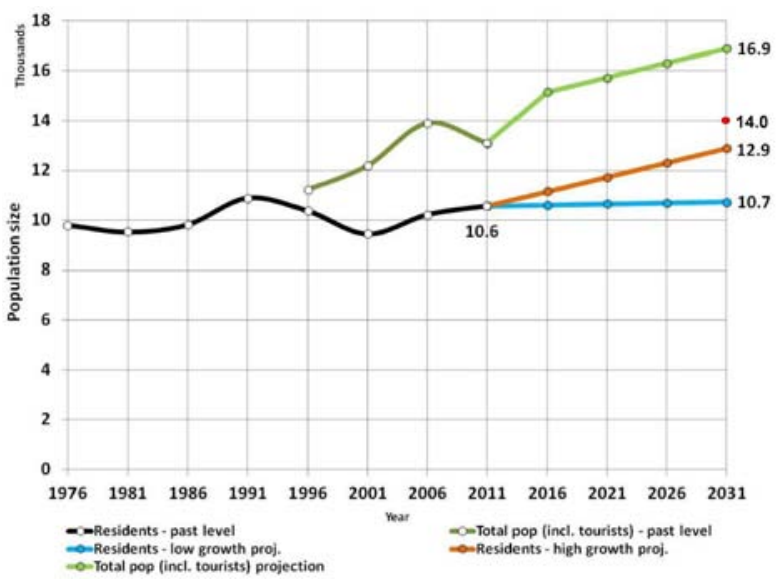

FIGURE 3 RAROTONGA POPULATION PROJECTIONS 2011 - 2031 (DEMMKE, 2013)

It has been assumed that demand remains static between the existing and future scenarios for institutional, industrial and agricultural demands. Residential and tourist demands are expected to increase as the residential population and visitor numbers increase as agreed during the Te Mato Vai technical workshop (Te Mato Vai Technical, 2012). Non-revenue water is expected to decrease as leakage and unmetered water use reduces. The demand allocations, set out in the following section for the 2031 scenario, represent a peak day scenario. However, due to uncertainty regarding the proportion of leakage and water loss in the existing network and the corresponding figures for 2031, once NRW reduction 
strategies have been employed, We has scaled up the demand in simulations by an additional $30 \%$ as a contingency measure to account for unforeseen increases in demand over the design horizon, or persistent problems with non-revenue water at higher than expected levels.

Total demand for 2031 is $11,200 \mathrm{~m}^{3} / \mathrm{d}$ with additional NRW demand of $1,120 \mathrm{~m}^{3} / \mathrm{d}$ giving a total future demand of 12,320 $\mathrm{m}^{3} / \mathrm{d}$ - refer Figure 4.

Demand 2031 - 12,300 m³/d

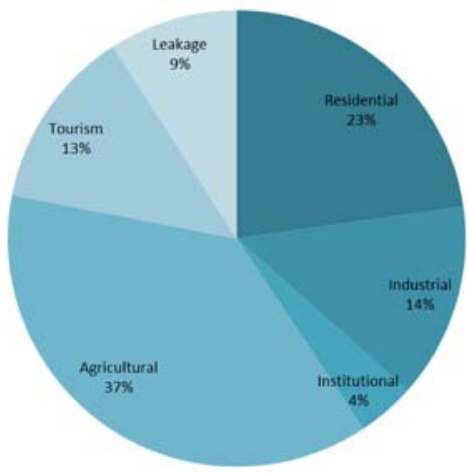

FIGURE 42031 DEMAND DISTRIBUTION

\section{B. Preliminary reservoir design}

Guidelines developed during the Te Mato Vai technical workshop set a target of $36,000 \mathrm{~m}^{3}$ of raw water storage on Rarotonga, the equivalent of 3 days of supply at peak demand (Te Mato Vai Technical, 2012).

Existing reservoirs potentially contribute more than 14,000 $\mathrm{m}^{3}$ capacity. The large open Akaoa reservoir makes up a large proportion of this storage with an estimated volume of $10,000 \mathrm{~m}^{3}$. The Akaoa reservoir has been decommissioned however, and has not been considered a part of the required 3 days storage. The reservoir reportedly never filled due to inadequate flow from the Muriavai intake and high evaporation losses. The Takuvaine reservoir is currently in service and contributes $2,500 \mathrm{~m}^{3}$ of storage; however, it is reportedly in poor condition. 7 smaller distribution tanks are distributed around the island, 5 of which are currently in service.

Proposed reservoir volumes to provide at least the required (Te Mato Vai Technical, 2012) 36,000 $\mathrm{m}^{3}$ of raw water storage. Our model included an additional $1,215 \mathrm{~m}^{3}$ of existing network storage in the future 2031 model.

Reservoir sizes were derived using an iterative process beginning with a volume equivalent to three times the maximum daily yield of the corresponding intake. Storage was subsequently reduced at intakes where model outputs indicated that the yield of a source was inadequate to fill the tank volume under peak demands. The process was repeated until the target volume of $36,000 \mathrm{~m}^{3}$ was achieved.

\section{Preliminary trunkmain design}

Our 2031 model includes proposed upgrades to the asbestos cement pipes that remain in service in Rarotonga's network. The 5 PVC trunkmains installed in 1993 are adequately sized and are considered a lower priority for upgrade. The Takuvaine trunkmain has recently been upgraded to a $200 \mathrm{~mm}$ DI pipe. No further upgrades have been considered for this line. Pipes upgrades have been sized to keep velocities in the trunkmains below $1.0 \mathrm{~m} / \mathrm{s}$ at peak demand. Trunkmain details are given in Figure 5.

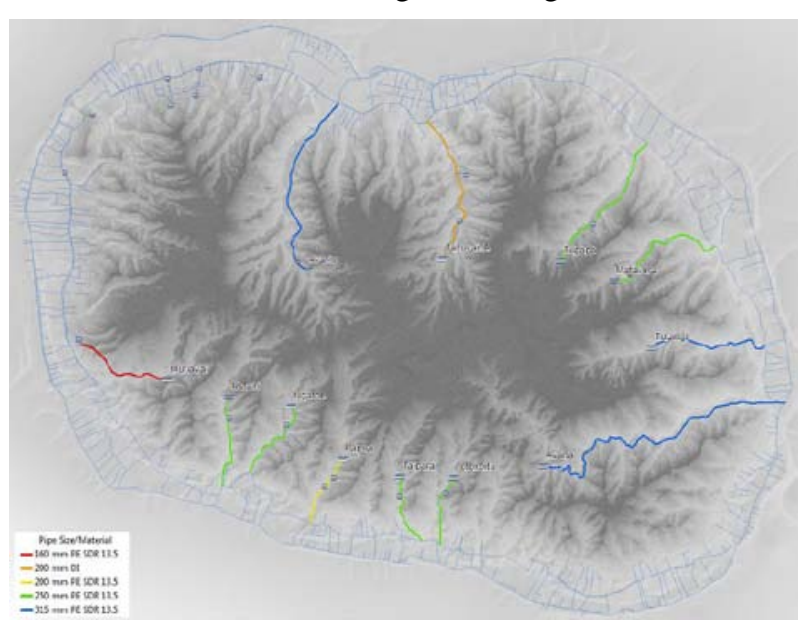

FIGURE 5 RAROTONGA TRUNKMAIN UPGRADES

\section{Analysis and performance of system in 2031}

The future model scenario incorporating;

- the ringmain and trunkmain upgrades;

- $\quad$ additional storage at the intakes; and

- $\quad$ pressure reducing valves along the trunkmains.

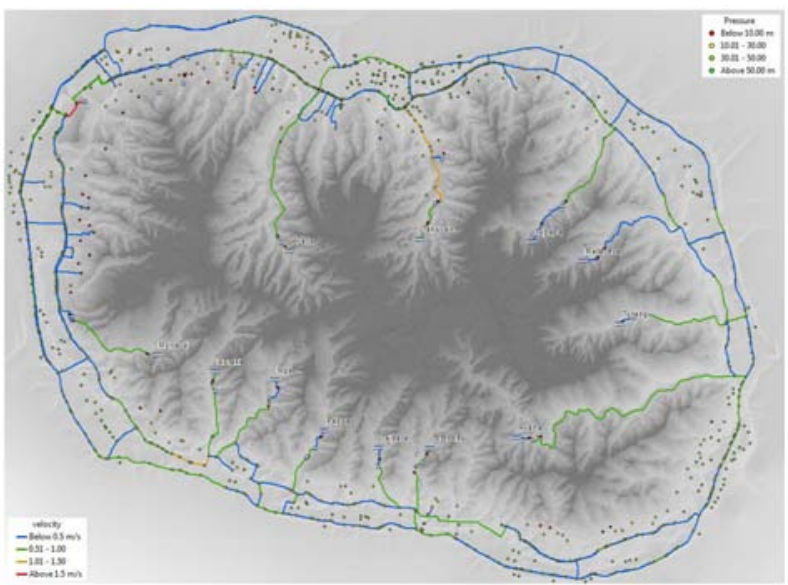

FIGURE 62031 NETWORK PERFORMANCE

High velocities in the trunkmains and the associated head losses are greatly reduced and the additional head available at the intakes resolves the majority of pressure problems around the island. Those properties still receiving less than adequate water pressures are all located at elevations above $30 \mathrm{~m}$. Velocities in the ringmains and trunkmains are kept below 1.0 $\mathrm{m} / \mathrm{s}$ in most cases with the Takuvaine trunkmain and small sections of the interior ring showing velocities greater than 1.0 $\mathrm{m} / \mathrm{s}$ but still below $1.5 \mathrm{~m} / \mathrm{s}$. The short section of pipework 
connecting the Sanatorium distribution tank with the inner ring main experiences high velocities above $1.5 \mathrm{~m} / \mathrm{s}$ as it rapidly fills and discharges. This section of pipe could be considered for upgrade but is outside of the scope of the current hydraulic analysis.

\subsection{Recommendations from hydraulic analysis}

Upon the completion of the proposed ringmain upgrades, the order in which subsequent upgrades are undertaken has significant impacts regarding the level of service the network has the capacity to provide. The works should be scheduled in such a way that the projects delivering the greatest hydraulic benefit are prioritised. From the initial hydraulic analysis we recommends the following projects as a high priority:

- The installation of raw water storage at Avana and Turangi due to the consistent yield and high elevation of these sources.

- Upgrades to the Kia Orana reservoir at Takuvaine due to the intakes location as the primary source serving the project city area and the reportedly poor condition of the existing Takuvaine reservoir which sits at a relatively low elevation.

- Data presented by the ADB (refer to Section 5.1.2) indicates that the Taipara intake is the most consistent source on the Southern Coast. For this reason, installation of raw water storage at Taipara intake to improve the security of supply and pressures on the Southern Coast and in particular the South Western region of the network.

\section{E. Water Network Recommendations}

Through hydraulic analysis to the design horizon of 2031, and after consultation with the different stakeholder groups of Te Mato Vai, the government has identified 64 projects as part of the renewal and upgrade of Rarotonga's water distribution network. Identified projects include the ringmain upgrades and subsequent network upgrade projects as follows:

- All of Rarotonga's intakes and trunkmains have been recommended for refurbishment and replacement with the exception of the Takuvaine intake which was completed as part of the Project City upgrades;

- Treatment works and storage reservoirs are required at each of the intakes; and

- The installation of PRVs on the intake lines, flow meters and backflow prevention devices is recommended to facilitate effective management of the network.

A number of smaller and peripheral projects have been identified including:

- The continuation of the subsidised private water tanks project;

- The installation of local booster pumps to supply properties over 30m above mean sea level;
- Initiatives to address customer side leakage across Rarotonga; and

- The implementation of Supervisory Control and Data Acquisition Systems (SCADA)

\section{F. Project Prioritisation}

Upon the completion of the proposed ringmain upgrades, the order in which subsequent upgrades are undertaken has significant impacts regarding the level of service the network has the capacity to provide. The works should be scheduled in such a way that the projects delivering the greatest hydraulic benefit are prioritised. From the initial hydraulic analysis we recommends the following projects as a high priority:

- The installation of raw water storage at Avana and Turangi due to the consistent yield and high elevation of these sources.

- Upgrades to the Kia Orana reservoir at Takuvaine due to the intakes location as the primary source serving the Project City area and the reportedly poor condition of the existing Takuvaine reservoir which sits at a relatively low elevation.

- Installation of raw water storage at Taipara intake to improve the security of supply and pressures in the South Western region of the network.

\section{G. Water Treatment}

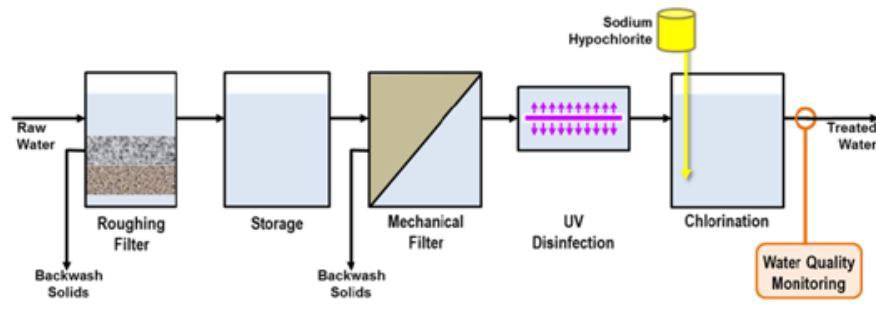

FIGURE 7 OVERALL TREATMENT AND DISTRIBUTION PROCESS RECOMMENDATION SUMMARY

Recommendations are given for water treatment unit processes, distribution system infrastructure and operations strategies to provide and maintain drinking water quality in the Rarotonga water supply system.

The proposed treatment strategies offer a multi-barrier approach to remove contaminants from the water source and maintain quality after treatment and prior to delivery to consumers. The proposed treatment processes aim at the following objectives, and are further detailed below:

- Particle removal that can withstand storm events which cause highly turbid water,

- Removal (by filtration) and inactivation (by primary disinfection) of microorganisms, and most importantly, pathogens,

- Residual disinfection to protect the treated water against pathogen introduction into the network during water distribution and also inhibit microbial regrowth, 
- Distribution system control and water quality monitoring to ensure compliance with water quality goals and the ability for operations staff to know when quality degrades,

- Water storage to ensure that peak demand is met, but also to stop treatment during storm events that bring overly turbid water that may compromise the treatment steps.

Options are proposed for both mechanical filtration and disinfection. These options are categorised as the minimum requirement (that which should be installed to meet minimum water quality needs) and the recommended option (that which should be installed to allow for a more robust level of treatment and more stable protection of water quality).

Further considerations which are presented include treatment waste residual management, backflow prevention, network system operation, water quality monitoring and operator training.

\section{GOVERNANCE}

A review was undertaken of the current governance and management arrangements for water services on Rarotonga.

As part ADB TA7287-COO "Improving the Delivery of Infrastructure Services”, a national policy for water was drafted and issued for comment on the 30th July 2010. The draft policy proposes the establishment of a Public Utilities Authority (PUA) by first transferring responsibility to the SOE Te Aponga Uria (TAU) who is currently responsible for electricity, and then enacting legislation to transform into a PUA that would be responsible for the delivery of power, water supply, sanitation and solid waste services on Rarotonga.

This approach would make good sense, especially when the practicalities of introducing a cost recovery regime for water are considered. The systems, processes and customer interaction requirements will be very similar for water billing to those already in place at TAU and these could be extended to water customers.

NSDP 2011 - 2015 states that for Priority Area 2: Infrastructure Strategy No. 5 involves strengthening Asset Management and "We [the Cook Islands] will strengthen the management of our public assets. As a matter of priority we will develop and implement Asset Management planning frameworks in 2011-2015."

The implication of this strategy is that Asset Management needs to be embedded within the organisation and closely aligned with planning and development.

The adoption of Asset Management principles into the organisation design will internally separate the roles of:

1) The 'Asset Owner' role which sets the short and long term investment objectives for the assets.

2) The 'Asset Management' role which makes decisions to satisfy the Asset Owner objectives whilst managing the balance between asset life, levels of service and capital and operational expenditure.
3) The 'Asset Service Provider' which provides services to satisfy the decisions made by the Asset Manager

This translates into the suggested organisation chart for water supply services below.

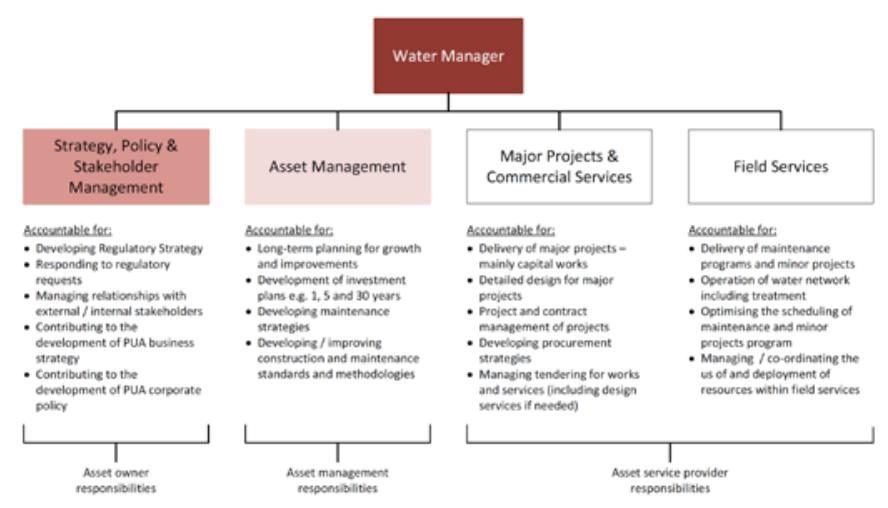

FIGURE 8 PUA WATER COMPONENT ORGANISATION STRUCTURE

While these roles are separated out they should be linked so that there is alignment across the organisation. Asset Management is a function that should be embedded across the entire organisation. The roles or functions are not necessarily attributable to individual persons and are likely to be spread across multiple persons.

The move towards a PUA that will charge for water and upgrading the water system to a potable standard will require legislation to be enacted to protect public health, prevent water wastage and manage Rarotonga's groundwater resources.

\section{NON-REVENUE WATER LOSSES}

Over the last 10 years MOIP has systematically replaced the reticulation mains on Rarotonga; the final sections in Avarua have been completed as part of Project City. Following the water system renewals, as seen recently in Avana, there are issues with leakage on private pipework. Much of the customer side pipework is old and its condition is unknown.

Therefore, non-revenue water has been primarily associated with residential properties. Based on previous work it has been assumed that leakage at the point of supply accounts for the majority of water loss from the system, estimated at anywhere between $40-70 \%$ losses.

Recommendations have been presented for non-revenue water loss management, including the commencement of a customer-side leakage programme.

\section{QUALITY AND STANDARDS}

The Te Mato Vai project is a significant investment for the Cook Islands and material components should be to a high quality, correct specification and installed correctly. The ringmain has been designed by CCECC and has been designed to Chinese material specifications and the construction standards proposed are Chinese. The Government of the Cook Islands uses Australian and New Zealand Standards. 
MOIP has undertaken substantial work during and after Project City to ensure quality and standards have been produced for the water supply.

This paper includes standards which are complementary to the existing standards and should be read in conjunction with those outlined above.

\section{REFERENCES}

[1] WHO. (2011). Guidelines for drinking water quality - 4th edition. Geneva: World Health Organization. ACENZ. (2004). Fee Guidelines for Consulting Engineering Services. Wellington.

[2] WHO. (2003). Chlorine in drinking-water. Background document for preparation of WHO. Geneva: World Health Organisation.

[3] Heinrich, M. \&. (2010). Auckland Water Use Study: Monitoring of residential water end uses. New Zealand Sustainable Building Conference 2010. BRANZ.

[4] New Zealand Fire Service. (2008). Firefighting Water Supplies Code of Practice. 